\title{
ГОЛОВНОГО МОЗГА
}

\author{
Киндалева О.Г. (kindaliova.volha@mail.ru),Пронько T.П. (tanya_pronko@mail.ru), \\ Степуро T. Л. (mikhno_t@yahoo.com) \\ УО «Гродненский государственный медицинский университет», Гродно, Беларусь
}

Введение. С полиморфизмом генов эндотелиальной NO-синтазы (е-NOS) (G894T, T786C) и гена эндотелина-1 (EDN-1) (G5665T) у паџиентов с артериальной гипертензией (АГ) может быть связан разный ответ на эндотелиотропную терапию (ЭТ).

Цель исследования. Изучить взаимосвязь полиморфизма генов эндотелиальной NO-синтазы (G894T, T786C) и гена эндотелина-1 (G5665T) с эффективностью терапии у пациентов с АГ после перенесенного инфаркта головного мозга.

Материал и методы. Обследованы 65 человек с АГ II степени, риск 4, после перенесенного инфаркта головного мозга. У всех пациентов определены генотипы генов е-NOS (G894T, T786C) и гена EDN-1 (G5665T), проведена оценка функции эндотелия и параметров жесткости сосудистой стенки до и после 12 недель ЭТ в подгруппах гомозигот по доминантным аллелям (ПГА) и в подгруппах, содержащих рецессивную аллель (ПГВ).

Результаты. У пащиентов с ПГВ генов эндотелиальной NO-синтазы (e-NOS) (G894T, T786C) и гена эндотелина-1(EDN-1) (G5665T) не наблюдалось достоверного прироста эндотелийзависимой вазодилатации (ЭЗВД) и прочент достижения иелевых значений данного параметра был ниже по сравнению с ПГА. У пациентов у ПГВ G5665T гена EDN-1 не наблюдалось достоверного снижения скорости распространения пульсовой волны (СРПВ) и процент достижения цүелевых значений данного параметра был ниже по сравнению с $\Pi Г A$.

Bыводы. Полиморфизм генов G894T гена е-NOS, T786C гена е-NOS и G5665T гена EDN-1 не связан с гипотензивным эффектом препаратов. Выявлена взаимосвязь G894T гена е-NOS, T786C гена е-NOS и G5665T гена $E D N-1$ с эффективностью коррекции дисфункиии эндотелия, проявляющейся отсутствием достоверного прироста ЭЗВД у носителей генотипов с реиессивныли аллелями. Выявлена взаимосвязь G5665T гена EDN-1 с эффективностью коррекции повышенной СРПВ, которая проявляется отсутствием достоверного снижения данного параметра у носителей генотипов с рецессивными аллелями.

Ключевые слова: полиморфизм генов эндотелиальной NO-синтазы (G894T, T786C) и гена эндотелина-1, жесткость сосудистой стенки, дисфункция эндотелия, эндотелиотропная терапия, артериальная гипертензия, ишемический инфаркт головного мозга.

\section{Введение}

Лечение артериальной гипертензии (АГ) должно быть направлено на коррекцию поражения органов-мишеней, важнейшим из которых является сосудистая стенка [1]. Жесткость сосудистой стенки отражает степень ремоделирования сосудистого звена, а ее повышение способствует развитию осложнений АГ и ухудшению прогноза [2]. Повышение жесткости сосудистой стенки тесно связано с функциональной активностью эндотелия [3]. Несмотря на внедрение в клиническую практику все более совершенных препаратов, обладающих эндотелиотропным действием, у значительной части пациентов сложно достичь регрессии ремоделирования сосудистой стенки. Способствовать этому могут разные факторы, в том числе и фармакогенетические [4]. Так как гены эндотелиальной NO-синтазы (G894T, T786C) и ген эндотелина-1 (G5665T) являются генами, непосредственно участвующими в регуляции функции эндотелия, возможно, с их полиморфизмом может быть связан разный ответ на эндотелиотропную терапию.

Цель исследования - изучить взаимосвязь полиморфизма генов эндотелиальной NO-синта- зы (G894T, T786C) и гена эндотелина-1 (G5665T) с эффективностью терапии у пациентов с АГ после перенесенного инфаркта головного мозга.

\section{Материал и методы}

Проведено проспективное открытое рандомизированное одноцентровое исследование. Рандомизация проводилась простым способом. Обследование проходило на базе кафедры пропедевтики внутренних болезней Гродненского государственного медицинского университета (ГрГМУ). Все обследуемые подписывали информированное согласие на участие в исследовании, протокол которого был одобрен комитетом по биомедицинской этике ГрГМУ.

Обследованы 65 человек с АГ ІІ степени, риск 4 после перенесенного инфаркта головного мозга (атеротромботический подтип) давностью более 6 месяцев, из них 46 мужчин, 21 женщина. Всем пациентам проведено исследование полиморфизма G984T гена эндотелиальной NO-синтазы (е-NOS), T786C гена е-NOS и G5665T гена эндотелина-1 (EDN-1).

Пациенты в течение 12 недель получали эндотелиотропную терапию в виде антигипертен- 
зивных препаратов, включающих ингибиторы ангиотензинпревращающего фермента (иАПФ) - лизиноприл либо периндоприл, антагонисты кальциевых каналов (АКК) - амлодипин и тиазидоподобный диуретик (ТД) - индапамид, и липидснижающую терапию (статины (аторвастатин) либо статины (розувастатин) в сочетании с эзетимибом).

Всем пациентам проводилось общеклиническое обследование, включавшее общий осмотр, измерение офисного артериального давления (АД) - систолического артериального давления (САД) и диастолического артериального давления (ДАД), роста, массы тела. Рассчитывался индекс массы тела по формуле Кетле (вес в кг/ рост в метрах $\left.{ }^{2}\right)$, проводилась регистрация ЭКГ в 12 стандартных отведениях. Выполнялся биохимический анализ крови с определением общего холестерина, мочевины, креатинина. Скорость клубочковой фильтрации рассчитывалась по формуле CKD-EPI [5].

Измерение эндотелийзависимой вазодилатации (ЭЗВД) и скорости распространения пульсовой волны (СРПВ) по сосудам мышечного типа осуществлялось с помощью аппаратно-программного комплекса «Импекард-М» (Беларусь) [6]. Сердечно-лодыжечный сосудистый индекс (СЛСИ) у обследуемых лиц определялся при помощи сфигмоманометра-сфигмографа VaSera VS-1500N Fukuda Denshi (Япония) [7]. Исследование уровня эндотелина-1 проводили с помощью набора для иммуноферментного анализа Human EDN1 (Endothelin-1) ELISA Kit. Диапазон измерения уровня эндотелина-1 в данном набоpe 1,25-80 пг/мл. Все исследования проводились дважды: исходно и через 12 недель терапии.

Генотипирование выделенных из крови образцов ДНК выполнено методом полимеразной цепной реакции с детекцией результата в режиме реального времени с использованием набора реактивов производства «Синтол», РФ.

Статистическая обработка результатов исследования осуществлялась с помощью пакета прикладных программ «STATISTICA10.0». Представление данных соответствовало характеру их распределения: при нормальном (по критерию Колмогорова-Смирнова с поправкой Лиллиефорса) - в виде среднего значения и стандартного отклонения $(\mathrm{M} \pm \mathrm{SD})$, при отличном от нормального - в виде медианы (Me), нижнего и верхнего квартилей (LQ; UQ). При оценке достоверности различий в сравниваемых подгруппах при нормальном распределении использовали параметрический критерий Стьюдента (t). При отсутствии нормального распределения сравнение показателей проведено с использованием непараметрического критерия Манна-Уитни (Z). Достоверность различий количественных показателей определялась при помощи критерия Вилкоксона (сравнение двух связанных групп). Данные, представленные в виде \%, сравнивали с помощью Difference tests между двумя пропорциями. За критический уровень достоверности нулевых гипотез при исследовании принималось значение $\mathrm{p} \leq 0,05$. Для оценки соответствия равновесию Харди-Вайнберга использовали критерий $\chi^{2}$.

\section{Результаты и обсуждение}

В таблице 1 показано распределение частоты генотипов и аллелей в каждой группе.

Распределение генотипов полиморфных локусов G894T гена e-NOS $\left(\chi^{2}=0,033 ; \mathrm{p}=0,85\right)$, T786C гена e-NOS $\left(\chi^{2}=1,57 ; \mathrm{p}=0,2\right)$, и полиморфного локуса G5665T гена EDN-1 $\left(\chi^{2}=2,12\right.$; $\mathrm{p}=0,14)$ соответствовали ожидаемому равновесию Харди-Вайнберга.

В таблице 2 представлена клиническая характеристика исследуемых групп.

Как видно из таблицы 2, подгруппы всех полиморфизмов исследуемых генов сопоставимы по полу, возрасту, удельному весу курящих лиц, антропометрическим данным, индексу массы тела, окружности талии и по уровню общего холестерина. В ПГВ полиморфного варианта G894T гена e-NOS скорость клубочковой фильтрации была достоверно ниже по сравнению с ПГА. В ПГВ полиморфного варианта Т786C гена e-NOS уровень глюкозы, креатинина был достоверно выше, а скорость клубочковой фильтрации - достоверно ниже по сравнению с ПГА.

Для оценки эффективности терапии пациенты были разбиты на подгруппы: генотипы, где выявлены доминантные аллели, обозначены подгруппой А (ПГА); генотипы, где присутствовали рецессивные аллели - подгруппой В (ПГВ).

Далее нами произведен анализ характера принимаемой терапии и среднесуточных доз препаратов в исследуемых подгруппах.

Характер принимаемой антигипертензивной терапии во всех группах приведен в таблице 3 .

Как видно из таблицы 3 , удельный вес и состав тройных, двойных и тройных фиксированных комбинаций в подгруппах всех исследуемых групп не имел достоверных различий.

В таблице 4 приведены среднесуточные дозы принимаемых препаратов.

Как видно из таблицы 4, среднесуточные дозы препаратов также не имели достоверных различий в подгруппах.

В таблице 5 представлена динамика параметров жесткости сосудистой стенки у обследуемых лиц в зависимости от полиморфизма исследуемых генов.

Таблица 1. - Распределение частот генотипов и аллелей

\begin{tabular}{|c|c|c|c|c|c|}
\hline \multicolumn{2}{|c|}{$\begin{array}{c}\text { Генотипы, } \\
\text { аллели G894T } \\
\text { гена е-NOS }\end{array}$} & \multicolumn{2}{c|}{$\begin{array}{c}\text { Генотипы, аллели T786C } \\
\text { гена е-NOS }\end{array}$} & \multicolumn{2}{c|}{$\begin{array}{c}\text { Генотипы, } \\
\text { аллели G865T } \\
\text { гена EDN-1 }\end{array}$} \\
\hline GG & $35(53,8 \%)$ & TT & $29(44,6 \%)$ & GG & $42(64,6 \%)$ \\
\hline GT & $25(38,5 \%)$ & TC & $32(49,2 \%)$ & GT & $18(27,7 \%)$ \\
\hline TT & $5(7,7 \%)$ & CC & $4(6,2 \%)$ & TT & $5(7,7 \%)$ \\
\hline Аллель G & $95(73,1 \%)$ & Аллель C & $90(69,2 \%)$ & Аллель G & $102(78,5 \%)$ \\
\hline Аллель T & $35(26,9 \%)$ & Аллель T & $40(30,8 \%)$ & Аллель T & $28(21,5 \%)$ \\
\hline
\end{tabular}


Таблица 2. - Клиническая характеристика исследуемых групп

\begin{tabular}{|c|c|c|c|c|c|c|}
\hline \multirow{2}{*}{ Показатели } & \multicolumn{2}{|c|}{$\begin{array}{l}\text { Полиморфный вариант G894T } \\
\text { гена е-NOS }\end{array}$} & \multicolumn{2}{|c|}{$\begin{array}{l}\text { Полиморфный вариант } \\
\text { T786C гена е-NOS }\end{array}$} & \multicolumn{2}{|c|}{$\begin{array}{l}\text { Полиморфный вариант } \\
\text { G865T гена EDN-1 }\end{array}$} \\
\hline & $\begin{array}{l}\text { ПГ А } \\
\mathrm{n}=35\end{array}$ & $\begin{array}{l}\text { ПГ В } \\
\mathrm{n}=30\end{array}$ & $\begin{array}{l}\text { ПГ А } \\
\mathrm{n}=29\end{array}$ & $\begin{array}{l}\text { ПГ В } \\
\mathrm{n}=36\end{array}$ & $\begin{array}{l}\text { ПГ А } \\
\mathrm{n}=42\end{array}$ & $\begin{array}{l}\text { ПГ В } \\
\mathrm{n}=23\end{array}$ \\
\hline Пол (мужчины/женщины), n & $25 / 10$ & $19 / 11$ & $20 / 9$ & $24 / 12$ & $28 / 14$ & $16 / 7$ \\
\hline Возраст, лет & $61,09 \pm 10,0$ & $61,63 \pm 11,59$ & $60,62 \pm 11,92$ & $61,92 \pm 9,72$ & $62,36 \pm 9,62$ & $59,48 \pm 12,41$ \\
\hline Продолжительность АГ, лет & $20,42 \pm 9,73$ & $21,91 \pm 9,64$ & $21,17 \pm 9,03$ & $22,66 \pm 9,95$ & $22,58 \pm 11,70$ & $20,27 \pm 10,15$ \\
\hline Курящие лица, n & $12(34,3 \%)$ & $10(33,3 \%)$ & $11(37,9 \%)$ & $11(30,6 \%)$ & $15(34,1 \%)$ & $7(30,4 \%)$ \\
\hline Рост, см & $169,75 \pm 8,16$ & $170,20 \pm 8,57$ & $170,8 \pm 8,49$ & $169,25 \pm 8,17$ & $169,26 \pm 8,57$ & $171,23 \pm 7,78$ \\
\hline Вес, кг & $80,94 \pm 12,24$ & $80,83 \pm 16,63$ & $80,59 \pm 14,21$ & $81,14 \pm 14,47$ & $80,57 \pm 13,29$ & $81,47 \pm 16,14$ \\
\hline Индекс массы тела, кг/м² & $27,83 \pm 3,33$ & $27,99 \pm 4,01$ & $27,40 \pm 4,02$ & $28,31 \pm 3,3,89$ & $28,02 \pm 3,61$ & $27,69 \pm 4,55$ \\
\hline Окружность талии (см) & $93,60 \pm 14,07$ & $95,4 \pm 18,32$ & $93,21 \pm 15,57$ & $95,42 \pm 16,61$ & $93,76 \pm 4,94$ & $95,65 \pm 5,06$ \\
\hline Глюкоза (ммоль/л) & $4,86 \pm 0,50$ & $5,16 \pm 0,93$ & $4,69 \pm 0,49$ & $5,26 \pm 0,79 * *$ & $4,94 \pm 0,81$ & $5,05 \pm 0,54$ \\
\hline Общий холестерин (ммоль/л) & $5,23 \pm 1,35$ & $5,38 \pm 1,37$ & $5,04 \pm 1,36$ & $5,52 \pm 1,33$ & $5,21 \pm 1,41$ & $5,45 \pm 1,25$ \\
\hline Креатинин (мкмоль/л) & $90,95 \pm 28,49$ & $98,10 \pm 16,47$ & $85,50 \pm 16,95$ & $104,24 \pm 36,21 *$ & $89,88 \pm 22,56$ & $101,05 \pm 36,45$ \\
\hline $\begin{array}{l}\text { Скорость клубочковой фильтрации } \\
\text { по формуле CKD-EPI (мл/ } \\
\text { мин/1,73м²) }\end{array}$ & $77,31 \pm 21,05$ & $61,06 \pm 23,47^{*}$ & $80,26 \pm 19,95$ & $62,48 \pm 25,42 *$ & $71,19 \pm 22,61$ & $72,71 \pm 24,24$ \\
\hline
\end{tabular}

Примечание: * достоверные различия между ПГА и ПГВ, где * $-p=\leq 0,05, * *-p=\leq 0,01$.

Tаблица 3. - Характер принимаемой антигипертензивной терапии

\begin{tabular}{|c|c|c|c|c|c|c|}
\hline \multirow{2}{*}{$\begin{array}{c}\text { Вид антигипертензивной } \\
\text { терапии }\end{array}$} & \multicolumn{2}{|c|}{$\begin{array}{c}\text { Полиморфный вариант G894T } \\
\text { гена е-NOS }\end{array}$} & \multicolumn{2}{|c|}{$\begin{array}{l}\text { Полиморфный вариант } \\
\text { T786C гена е-NOS }\end{array}$} & \multicolumn{2}{|c|}{$\begin{array}{l}\text { Полиморфный вариант } \\
\text { G865T гена EDN-1 }\end{array}$} \\
\hline & $\begin{array}{l}\text { ПГ А } \\
\mathrm{n}=35\end{array}$ & $\begin{array}{l}\text { ПГ В } \\
\mathrm{n}=30\end{array}$ & $\begin{array}{l}\text { ПГ А } \\
\mathrm{n}=29\end{array}$ & $\begin{array}{l}\text { ПГ В } \\
\mathrm{n}=36\end{array}$ & $\begin{array}{l}\text { ПГ А } \\
\mathrm{n}=42\end{array}$ & $\begin{array}{l}\Pi Г \text { В } \\
n=23\end{array}$ \\
\hline $\begin{array}{l}\text { Тройная нефиксированная } \\
\text { комбинация } \\
\text { (иАПФ +АКК+ ТД), n }\end{array}$ & $2(5,7 \%)$ & $3(10 \%)$ & $2(6,7 \%)$ & $3(8,3 \%)$ & $3(7,1 \%)$ & $2(8,7 \%)$ \\
\hline $\begin{array}{l}\text { Двойная нефиксированная } \\
\text { комбинация (иАПФ+ТД), } \mathrm{n}\end{array}$ & $12(34,3 \%)$ & $10(33,3 \%)$ & $10(34,5 \%)$ & $12(33,3 \%)$ & $14(33,3 \%)$ & $8(34,8 \%)$ \\
\hline $\begin{array}{l}\text { Двойная нефиксированная } \\
\text { комбинация } \\
\text { (иАПФ+ АКК), n }\end{array}$ & $10(28,6 \%)$ & $5(16,7 \%)$ & $7(24,1 \%)$ & $8(22,2 \%)$ & $9(21,4 \%)$ & $6(26,1 \%)$ \\
\hline $\begin{array}{l}\text { Тройная фиксированная } \\
\text { комбинация } \\
\text { (иАПФ + ТД+АКК), n }\end{array}$ & $11(31,4 \%)$ & $12(40 \%)$ & $10(34,5 \%)$ & $13(35,1 \%)$ & $16(38,1 \%)$ & $7(30,4 \%)$ \\
\hline
\end{tabular}

Примечание: иАПФ - ингибитор ангиотензинпревращчающего фермента; АКК - антагонист кальциевых каналов, ТД - тиазидоподобньй диуретик, $n$ - количество человек на данном виде терапии

Как видно из таблицы 5 , в подгруппах всех исследуемых полиморфизмов исходные показатели изучаемых параметров достоверно не различались. После 12 недель терапии уровень САД достоверно снизился во всех подгруппах полиморфных вариантов генов. Уровень ДАД достоверно снизился в обеих подгруппах полиморфных вариантов Т786C промотора гена e-NOS, G5665T гена EDN-1 и в ПГА полиморфного варианта G894T гена e-NOS, в то время как в ПГВ полиморфного варианта G894T гена e-NOS достоверного снижения ДАД не произошло. Дополнительно проведена оценка достижения целевых значений САД и ДАД в подгруппах (САД<140 мм рт. ст., ДАД<90 мм рт. ст.)

Целевых значений САД в ПГА и ПГВ G894T гена е-NOS достигли 80 и 76,7\%, соответственно, ПГА и ПГВ Т786C промотора гена e-NOS - 79,3 и $75 \%$, соответственно, в ПГА и ПГВ G5665T гена EDN-1 - 81 и 69,6\%, соответственно.

Целевых значений ДАД в ПГА и ПГВ G894T гена e-NOS достигли 77,1 и 76,7\%, соответственно, ПГА и ПГВ Т786С промотора гена e-NOS - 69,0 и $66,7 \%$, соответственно, в ПГА и ПГВ G5665T гена EDN-1 - 71,4 и 65,2\%, соответственно.

В ПГА и в ПГВ всех исследуемых генов процент достижения целевых уровней АД не различался, что дает основание предположить отсутствие влияния полиморфизма исследуемых генов на эффективность снижения АД.

Как видно из таблицы 5 , снижение уровня эндотелина-1 в плазме крови отмечено во всех подгруппах исследуемых генов.

Достоверный прирост ЭЗВД наблюдался только в ПГА полиморфных вариантов G894T 
Таблица 4. - Среднесуточные дозы принимаемых препаратов

\begin{tabular}{|c|c|c|c|c|c|c|}
\hline \multirow{2}{*}{$\begin{array}{c}\text { Название действующего } \\
\text { вещества препарата / } \\
\text { фиксированной } \\
\text { комбинации } \\
\text { антигипертензивных } \\
\text { средств }\end{array}$} & \multicolumn{2}{|c|}{$\begin{array}{l}\text { Полиморфный вариант } \\
\text { G894T гена e-NOS }\end{array}$} & \multicolumn{2}{|c|}{$\begin{array}{c}\text { Полиморфный вариант T786C гена } \\
\text { e-NOS }\end{array}$} & \multicolumn{2}{|c|}{$\begin{array}{c}\text { Полиморфный вариант } \\
\text { G865T гена EDN-1 }\end{array}$} \\
\hline & $\begin{array}{l}П Г А ~ \\
n=35\end{array}$ & $\begin{array}{l}П Г \mathrm{~B} \\
\mathrm{n}=30\end{array}$ & $\begin{array}{l}\text { ПГ А } \\
\mathrm{n}=29\end{array}$ & $\begin{array}{l}П Г \mathrm{~B} \\
\mathrm{n}=36\end{array}$ & $\begin{array}{l}П Г А ~ \\
n=42\end{array}$ & $\begin{array}{l}\text { ПГ В } \\
n=23\end{array}$ \\
\hline $\begin{array}{l}\text { Лизиноприл доза } \\
\text { (мг/сут) /n }\end{array}$ & $\begin{array}{c}20,77 \pm 9,54 \\
n=13\end{array}$ & $\begin{array}{c}26,15 \pm 9,54 \\
n=13\end{array}$ & $\begin{array}{c}23,33 \pm 10,73 \\
n=12\end{array}$ & $\begin{array}{c}24,29 \pm 10,89 \\
n=14\end{array}$ & $\begin{array}{c}22,9 \pm 10,47 \\
\mathrm{n}=17\end{array}$ & $\begin{array}{c}22,2 \pm 10,92 \\
\mathrm{n}=9\end{array}$ \\
\hline $\begin{array}{l}\text { Периндоприл доза } \\
\text { (мг/сут)/n }\end{array}$ & $\begin{array}{c}6,54 \pm 3,70 \\
\mathrm{n}=11\end{array}$ & $\begin{array}{c}5,6 \pm 2,19 \\
n=5\end{array}$ & $\begin{array}{c}6,86 \pm 1,95 \\
n=7\end{array}$ & $\begin{array}{c}7,11 \pm 1,76 \\
\mathrm{n}=9\end{array}$ & $\begin{array}{c}7,33 \pm 5,56 \\
\mathrm{n}=9\end{array}$ & $\begin{array}{c}7,71 \pm 4,39 \\
n=7\end{array}$ \\
\hline $\begin{array}{l}\text { Амлодипин доза } \\
(\text { мг/сут) /n }\end{array}$ & $\begin{array}{c}6,67 \pm 2,46 \\
n=12\end{array}$ & $\begin{array}{c}6,88 \pm 2,59 \\
n=8\end{array}$ & $\begin{array}{c}6,67 \pm 2,50 \\
n=9\end{array}$ & $\begin{array}{c}6,82 \pm 2,52 \\
n=11\end{array}$ & $\begin{array}{c}6,46 \pm 3,28 \\
n=12\end{array}$ & $\begin{array}{c}5,94 \pm 2,65 \\
n=8\end{array}$ \\
\hline $\begin{array}{l}\text { Индапамид доза } \\
\text { (мг/сут) /n }\end{array}$ & $\begin{array}{c}2,5 \\
n=14\end{array}$ & $\begin{array}{c}2,5 \\
n=13\end{array}$ & $\begin{array}{c}2,5 \\
n=12\end{array}$ & $\begin{array}{c}2,5 \\
n=15\end{array}$ & $\begin{array}{c}2,5 \\
n=17\end{array}$ & $\begin{array}{c}2,5 \\
n=10\end{array}$ \\
\hline $\begin{array}{l}\text { Периндоприл / } \\
\text { индапамид/ амлодипин } \\
\text { доза (мг/сут) /n }\end{array}$ & $\begin{array}{c}5,91 \pm 2,02 / \\
1,48 \pm 0,65 / \\
5,45 \pm 1,51 \\
\mathrm{n}=11\end{array}$ & $\begin{array}{c}5,83 \pm 1,95 / \\
1,46 \pm 0,49 / \\
5,41 \pm 1,44 \\
\mathrm{n}=12\end{array}$ & $\begin{array}{c}5,50 \pm 1,58 / 1,38 \\
\pm 0,40 / 5,00 \pm 1,58 \\
n=10\end{array}$ & $\begin{array}{c}6,15 \pm 2,20 / 1,54 \\
\pm 0,55 / 5,0 \pm 0,00 \\
n=13\end{array}$ & $\begin{array}{c}6,25 \pm 1,43 / 1,41 \\
\pm 0,58 / 5,63 \pm 1,53 \\
n=16\end{array}$ & $\begin{array}{c}6,43 \pm 1,61 / \\
1,61 \pm 0,39 / \\
5,00 \pm 0,00 \\
\mathrm{n}=7\end{array}$ \\
\hline
\end{tabular}

Примечание: $n$-количество человек, принимающчх данный гипотензивный препарат, мг/сут -миллиграмм в сутки

Taблица 5. - Параметры функции эндотелия, жесткости сосудистой стенки и АД в группах при исходном и повторном обследовании

\begin{tabular}{|c|c|c|c|c|c|c|}
\hline \multirow[t]{2}{*}{ Показатели } & \multicolumn{2}{|c|}{$\begin{array}{l}\text { Полиморфный вариант G894T гена } \\
\text { e-NOS }\end{array}$} & \multicolumn{2}{|c|}{$\begin{array}{l}\text { Полиморфный вариант T786C гена } \\
\text { e-NOS }\end{array}$} & \multicolumn{2}{|c|}{$\begin{array}{l}\text { Полиморфный вариант G865T гена } \\
\text { EDN-1 }\end{array}$} \\
\hline & $\begin{array}{l}\text { ПГ А } \\
\mathrm{n}=35\end{array}$ & $\begin{array}{l}\text { ПГ В } \\
\mathrm{n}=30\end{array}$ & $\begin{array}{l}\text { ПГ А } \\
\mathrm{n}=29\end{array}$ & $\begin{array}{l}\text { ПГ В } \\
\mathrm{n}=36\end{array}$ & $\begin{array}{l}\text { ПГ А } \\
\mathrm{n}=42\end{array}$ & $\begin{array}{l}\text { ПГ В } \\
\mathrm{n}=23\end{array}$ \\
\hline $\begin{array}{c}\text { САД } 1 \\
\text { мм рт. ст. }\end{array}$ & $140[130 ; 160]$ & $150[140 ; 160]$ & $150[140 ; 160]$ & $150[130 ; 160]$ & $150[140 ; 160]$ & $150[140 ; 160]$ \\
\hline $\begin{array}{c}\text { САД } \\
\text { мм рт. ст. }\end{array}$ & $\begin{array}{c}130[130 ; 140] \\
* * * *\end{array}$ & $\begin{array}{c}140[130 ; 140] \\
*\end{array}$ & $130\left[\begin{array}{c}{[130 ; 140]} \\
* * *\end{array}\right.$ & $\begin{array}{c}140[130 ; 140] \\
* *\end{array}$ & $\begin{array}{l}140[130 \\
140]^{* * * *}\end{array}$ & $\begin{array}{c}140[130 ; 140] \\
*\end{array}$ \\
\hline ДАД ${ }^{1}$ мм рт. ст. & $90[80 ; 90]$ & $90[90 ; 100]$ & $90[80 ; 90]$ & $90[90 ; 100]$ & $90[80 ; 100]$ & $100[80 ; 100]$ \\
\hline $\begin{array}{c}\text { ДАД } \\
\text { мм рт. ст. }\end{array}$ & $80[80 ; 90] * *$ & $80[80 ; 90]$ & $80[80 ; 90]^{*}$ & $80[80 ; 90]^{* *}$ & $80[80 ; 90]^{*}$ & $80[80 ; 90]^{*}$ \\
\hline $\begin{array}{c}\text { Эндотелин- } 1^{1} \\
\text { пг/мл }\end{array}$ & $12,4[9,0 ; 17,8]$ & $13,0[9,1 ; 19,8]$ & $11,6[6,3 ; 17,3]$ & $13,02[9,1 ; 25,1]$ & $12,4[9,0 ; 19,5]$ & $13,02[9,0 ; 19,53]$ \\
\hline $\begin{array}{c}\text { Эндотелин-12 } \\
\text { пг/мл }\end{array}$ & $\begin{array}{c}6,4 \\
{[4,9 ; 12,0]} \\
* *\end{array}$ & $\begin{array}{c}7,5 \\
{[4,9 ; 12,0]} \\
* *\end{array}$ & $\begin{array}{c}6,3 \\
{[3,1 ; 11,7]} \\
* * * *\end{array}$ & $\begin{array}{c}7,6 \\
{[4,5 ; 11,9]} \\
* * *\end{array}$ & $\begin{array}{c}5,32 \\
{[3,9 ; 10,8]^{* * *}}\end{array}$ & $\begin{array}{c}7,5 \\
{[4,3 ; 11,8]} \\
*\end{array}$ \\
\hline $\begin{array}{c}\text { ЭЗВД } 1 \\
\%\end{array}$ & $\begin{array}{c}-5,6 \\
{[-25,2 ; 9,5]} \\
\end{array}$ & $\begin{array}{c}-10,8 \\
{[-28,3 ; 1,6]} \\
\end{array}$ & $\begin{array}{c}-5,6 \\
{[-26,0 ; 20,6]}\end{array}$ & $\begin{array}{c}-11,6 \\
{[-30,1 ;-6,5]} \\
\end{array}$ & $\begin{array}{c}-13,1 \\
{[-26,0 ;-0,4]} \\
\end{array}$ & $\begin{array}{c}-20,5 \\
{[-29,7 ;-4,7]} \\
\end{array}$ \\
\hline $\begin{array}{c}\text { ЭЗВД } 2 \\
\%\end{array}$ & $\begin{array}{c}7,7 \\
{[-12,6 ; 14,3]} \\
*\end{array}$ & $\begin{array}{c}3,2 \\
{[-13,7 ; 19,3]}\end{array}$ & $\begin{array}{c}8,2 \\
{[-12,4 ; 24,2]} \\
* *\end{array}$ & $\begin{array}{c}5,2 \\
{[-4,5 ; 14,2]}\end{array}$ & $\begin{array}{c}6,7 \\
{[-12,6 ; 14,3]} \\
* *\end{array}$ & $\begin{array}{c}1,7 \\
{[-14,5 ; 20,9]}\end{array}$ \\
\hline $\begin{array}{c}\mathrm{CP}_{\mathrm{M}} / \mathrm{c} \\
\end{array}$ & $10,9[6,9 ; 15,0]$ & $11,7[5,9 ; 17,8]$ & $\begin{array}{c}10,15 \\
{[5,8 ; 15,5]}\end{array}$ & $10,1[6,7 ; 15,2]$ & $11,5[7,5 ; 17,8]$ & $11,9[6,4 ; 18,0]$ \\
\hline $\begin{array}{c}\mathrm{CP}_{\mathrm{M} / \mathrm{c}} \\
2\end{array}$ & $\begin{array}{c}6,4 \\
{[4,3 ; 9,0]} \\
* *\end{array}$ & $\underset{* *}{6,9[4,0 ; 9,0]}$ & $\begin{array}{c}5,4 \\
{[3,6 ; 9,0]} \\
* * *\end{array}$ & $\begin{array}{c}7,3 \\
{[4,2 ; 9,8]} \\
* *\end{array}$ & $\begin{array}{c}5,7 \\
{[4,0 ; 9,0]} \\
* * * *\end{array}$ & $\begin{array}{c}8,4 \\
{[4,3 ; 12,8]}\end{array}$ \\
\hline СлСИ $^{1}$ & $9,1[8,5 ; 9,9]$ & $9,2[8,2 ; 10,0]$ & $9,05[8,5 ; 9,9]$ & $9,2[8,2 ; 10,2]$ & $8,9[8,3 ; 9,5]$ & $9,2 \#[8,4 ; 10,1]$ \\
\hline СЛСИ ${ }^{2}$ & $8,5[6,6 ; 9,7] * *$ & $9,0[8,0 ; 9,5]$ & $8,6[7,4 ; 9,4] *$ & $8,9[7,9 ; 9,6] *$ & $8,3[6,9 ; 9,4] * *$ & $8,9[7,8 ; 9,7] * *$ \\
\hline
\end{tabular}

Примечания: САД - систолическое артериальное давление, ДАД - диастолическое артериальное давление, ЭЗВДэндотелийзависимая вазодилатачия, СРПВ - скорость распространения пульсовой волны, СЛСИ - сердечно-лодыжечный сосудистый индекс. *-достоверные различия внутри подгруппы до и после лечения, где * - $p \leq 0,05$, ** - $p \leq 0,01$, *** - $\leq \leq 0,001, * * * *-p \leq 0,001$. Индекс 1 - значение параметра до лечения, индекс 2 - после лечения, \#-достоверные различия по исходным показателям между подгруппами $А$ и $B$, где \#-p $\leq 0,05$. 
гена е-NOS, T786C промотора гена е-NOS и G5665T гена EDN-1.

На рисунках 1, 2 и 3 приведены проценты достижения целевых значений ЭЗВД в исследуемых подгруппах.

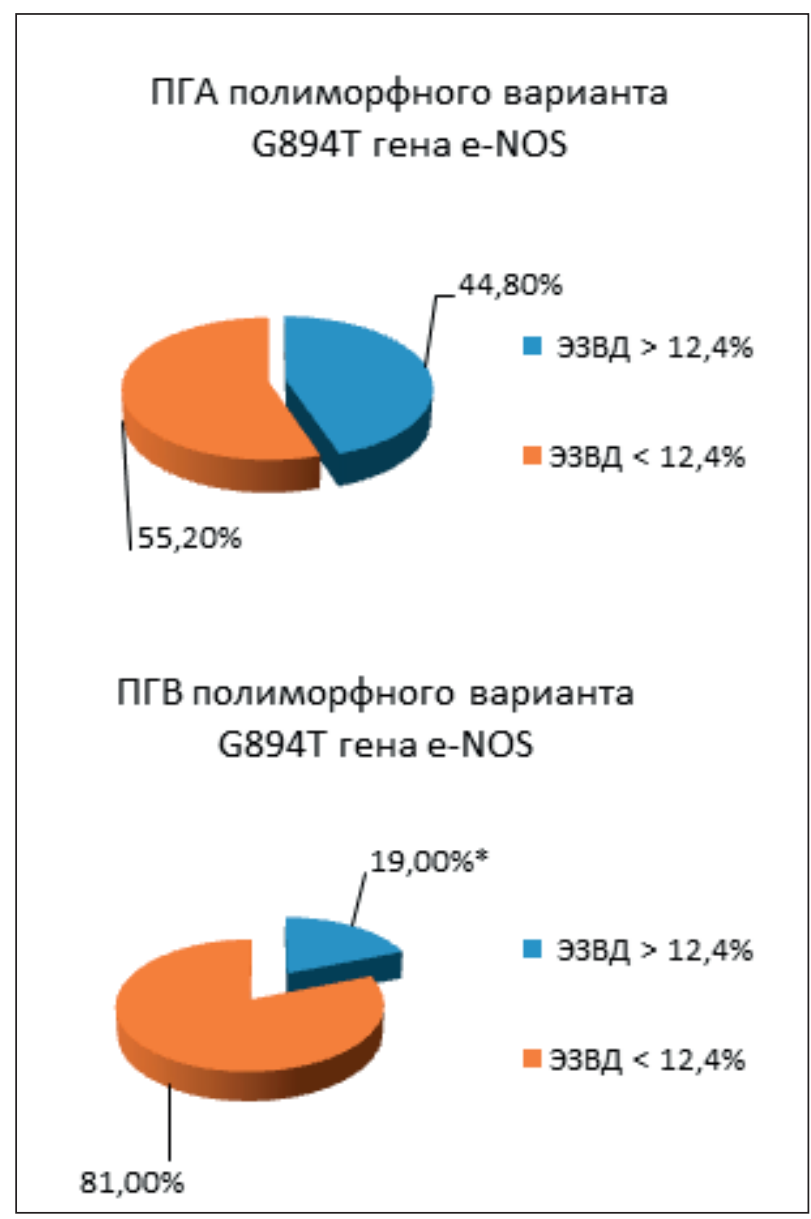

Рисунок 1. - Процент достижения целевых значений ЭЗВД в подгруппах полиморфного варианта G894T гена е-NOS

Примечание: * - достоверные различия между подгруппами А и В полиморфного варианта G894T гена е-NOS, где $*-p \leq 0,05$

Как видно из рисунка 1, в ПГВ полиморфных вариантов G894T гена e-NOS, T786C промотора гена e-NOS и G5665T гена EDN-1 целевых значений ЭЗВД (>12,4\%) [6] достигло меньшее количество пациентов по сравнению с ПГА (p1=0,0491, p2=0,0274 и p3 $=0,0216$, соответственно).

При глубоком анализе до лечения выявлена парадоксальная реакция на реактивную гиперемию в виде вазоспазма по полиморфному варианту G894T гена e-NOS в ПГА у 85,7\% лиц, в ПГВ - у 91,4\% лиц. После лечения парадоксальная реакция на реактивную гиперемию в виде вазоспазма сохранилась в большей степени у пациентов в ПГВ $(53,3 \%)$ по сравнению с пациентами в ПГА (31,4\%), p=0,0004. Парадоксальная реакция на реактивную гиперемию в виде вазоспазма по полиморфному варианту Т786C

\section{ПГА полиморфного варианта T786C гена е-NOS}

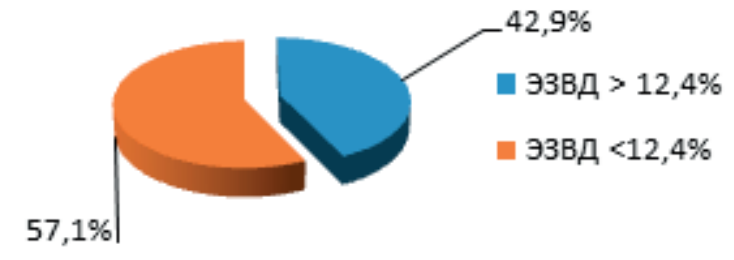

ПГВ полиморфного варианта T786C гена е-NOS

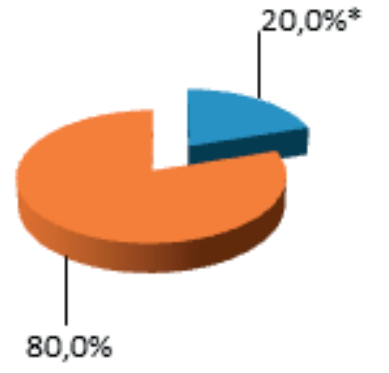

эзвд $>12,4 \%$

ш эзвд $<12,4 \%$

Рисунок 2. - Процент достижения целевых значений ЭЗВД в подгруппах полиморфного варианта Т786С промотора гена е-NOS

Примечание: * - достоверные различия между подгруппами А и В полиморфного варианта Т786С промотора гена $e-N O S$, где * $-p \leq 0,05$

промотора гена e-NOS была выявлена в ПГА у $86,2 \%$ лиц, в ПГВ - у 88,9\% лиц. После лечения парадоксальная реакция на реактивную гиперемию в виде вазоспазма сохранилась в большей степени у пациентов в ПГВ $(47,2 \%)$ по сравнению с пациентами в ПГА $(13,8 \%), \mathrm{p}=0,0042$. Парадоксальная реакция на реактивную гиперемию в виде вазоспазма по полиморфному варианту G5665T гена EDN-1 была выявлена в ПГА у $85,7 \%$ лиц, в ПГВ - у 91,3\% лиц. После лечения парадоксальная реакция на реактивную гиперемию в виде вазоспазма сохранилась в большей степени у пациентов в ПГВ $(52,2 \%)$ по сравнению с пациентами в ПГА $(23,8 \%), p=0,027$.

Как видно из таблицы 5 , после проведенной терапии СРПВ достоверно снизилась в обеих подгруппах полиморфного варианта G894T и T786C промотора гена e-NOS. Что касается полиморфного варианта G5665T гена EDN-1, то снижение СРПВ произошло только в ПГА. Была проведена также оценка достижения целевых значений СРПВ в подгруппах $(<10 \mathrm{~m} / \mathrm{c})[8,9]$.

Целевых значений СРПВ в ПГА и ПГВ G894T гена e-NOS достигли 82,6 и 80,0\%, соответственно, ПГА и ПГВ Т786С промотора гена e-NOS - 86,2 и 77,7\%, соответственно. Ниже приведен рисунок 4, отражающий процент до- 


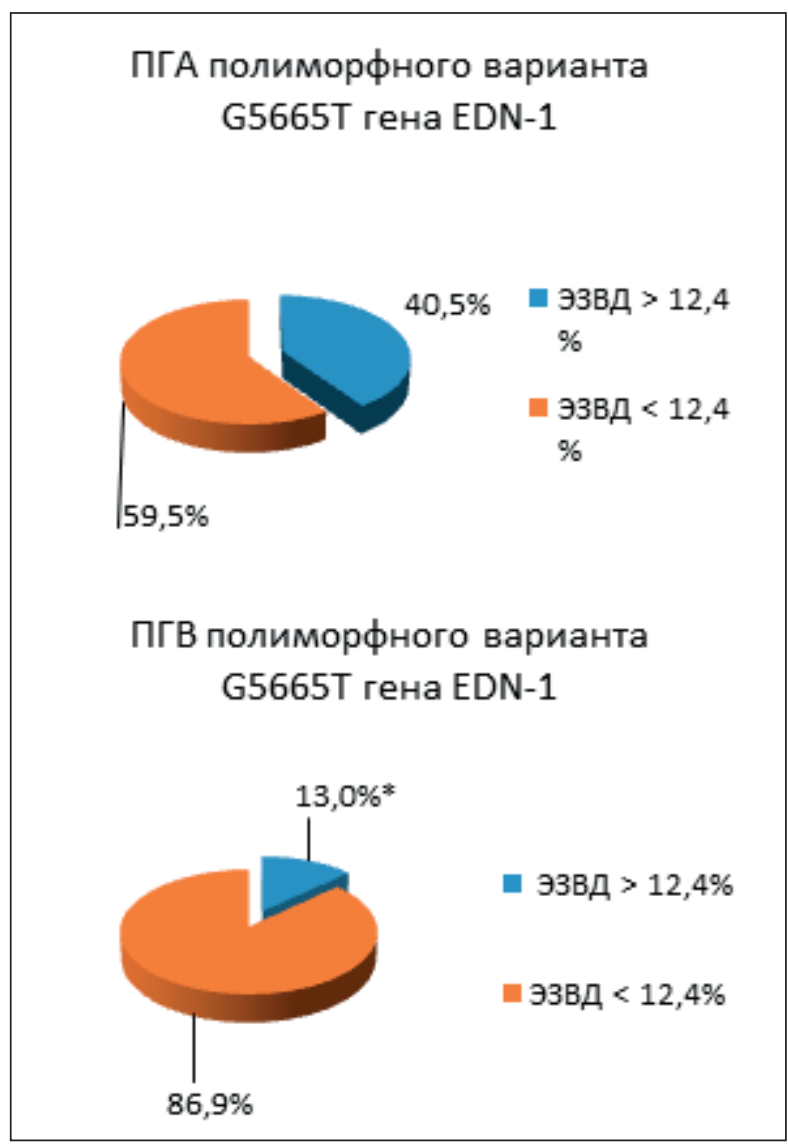

Рисунок 3. - Процент достижения целевых значений ЭЗВД в подгруппах полиморфного варианта G5665T гена $E D N-1$

Примечание: * - достоверные различия между подгруппами А и В полиморфного варианта G5665T гена EDN-1, где $*-p \leq 0,05$

стижения целевых цифр в подгруппах G5665T гена EDN-1.

В ПГВ полиморфного варианта G5665T гена EDN-1 целевых значений СРПВ достигло меньшее количество пациентов по сравнению с ПГА ( $\mathrm{p}=0,012)$. В ПГВ G5665T гена EDN-1 не произошло достоверного снижения СРПВ после проведенной терапии и процент достижения целевых значений был достоверно ниже спустя 12 недель терапии на фоне синхронного снижения САД в обеих подгруппах, что косвенно подтверждает влияние G5665T гена EDN-1 на лучшую эффективность коррекции процессов ремоделирования сосудистой стенки в артериях мышечного типа у носителей генотипа GG.

Как видно из таблицы 5, СЛСИ исходно в ПГВ полиморфного варианта G5665T гена EDN1 был достоверно выше по сравнению с ПГА. Однако при проведении дисперсионного анализа влияния полиморфного варианта G5665T гена EDN-1 на данный параметр не установлено. СЛСИ достоверно снизился в обеих подгруппах полиморфных вариантов Т786С промотора гена e-NOS и G5665T гена EDN-1, тогда как в полиморфном варианте G894T гена e-NOS достоверное снижение величины СЛСИ наблюдалось

\section{ПГА полиморфного варианта G5665T гена EDN-1}

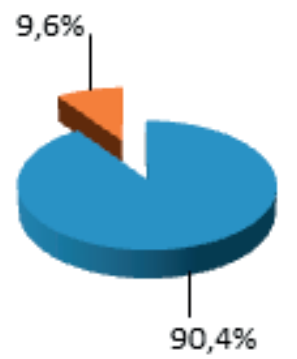

- $\mathrm{CP} \Pi \mathrm{B}<10 \mathrm{~m} / \mathrm{c}$

- $\mathrm{CP} \cap \mathrm{B}>10 \mathrm{~m} / \mathrm{c}$

\section{ПГВ полиморфного варианта гена G5665T EDN-1}

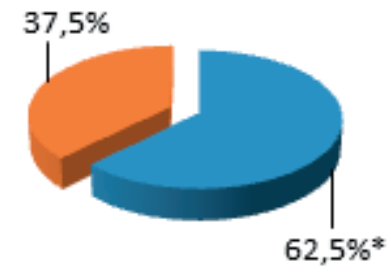

- $\mathrm{CP} \Pi \mathrm{B}<10 \mathrm{~m} / \mathrm{c}$

च $\mathrm{CP} \cap \mathrm{B}>10 \mathrm{~m} / \mathrm{c}$

Рисунок 4. - Процент достижения целевых значений ЭЗВД в подгруппах полиморфного варианта G5665T гена EDN-1

Примечание: * - достоверные различия между подгруппами А и В полиморфного варианта G5665T гена EDN-1, где $*-p \leq 0,05$

только в ПГА. Дополнительно проведена оценка достижения целевых значений СЛСИ в подгруппах $($ СЛСИ $<9)$.

Целевых значений СЛСИ в ПГА и ПГВ G894T гена е-NOS достигли 62,9 и 60,0\%, coответственно, ПГА и ПГВ Т786С промотора гена е-NOS - 60,0 и 58,3\%, соответственно, в ПГА и ПГВ G5665T гена EDN-1 - 54,7 и 60,9\%, соответственно.

Согласно литературным данным, прирост диаметра плечевой артерии у пациентов с генотипами CC и T786C промотора гена e-NOS, TT G894T гена е-NOS и генотипами TT G5665T гена EDN-1 достоверно ниже [10], а уровень эндотелина-1 в плазме крови - достоверно выше $[11,12]$. В нашем исследовании исходно нами не выявлено достоверных различий по уровню ЭЗВД и эндотелина-1 в плазме крови, что можно объяснить длительным приемом антигипертензивных препаратов и статинов пациентами до включения в исследование. Однако характерен тот факт, что даже при регулярном приеме препаратов исходно наблюдалась парадоксальная реакция на реактивную гиперемию в виде вазоспазма во всех исследуемых подгруппах, который поддался эффективной коррекции только 
у лиц с генотипами GG G894T гена е-NOS, CC T786C промотора гена е-NOS и GG G5665T гена EDN-1.

А. В. Хромова и др. в своем исследовании показали, что носители генотипа СС Т786С промотора гена e-NOS имеют склонность к периферическому вазоспазму [13]. В нашем исследовании в ПГВ данного полиморфного варианта наблюдался худший эффект в отношении коррекции парадоксальной реакции на реактивную гиперемию по сравнению с ПГА, что, скорее всего, повлекло за собой отсутствие эффективного снижения уровня ДАД у лиц с генотипами СС и ТС после проведенной терапии.

В литературе встречаются единичные работы, посвященные изучению связи полиморфизма локуса G984T гена e-NOS с поражением органов-мишеней, одним из которых является сосудистая стенка. Согласно данным Н. С. Пахомя, попытки связать структурную организацию данного гена с наличием ремоделирования стенки крупных сосудов при АГ не привели к успеху [14]. По данным Martinez-Godines A. et al., установлена связь между полиморфным вариантом G894T гена e-NOS c повышенной толщиной комплекса интима-медиа каротидных артерий в правой сонной артерии [15]. Яковлева Н. отмечает связь мутантного аллеля Т с увеличением СРПВ по артериям эластического и мышечного типа [16].

В нашем исследовании выявлено, что носители генотипов GG и GT G894T гена е-NOS хуже поддаются коррекции жесткости сосудов эластического типа, определяемому по СЛСИ. Однако при оценке достижения целевых значений по вышеуказанному параметру нами не получено достоверных различий в подгруппах, что говорит о необходимости исследования влияния полиморфизма G894T гена е-NOS на СЛСИ на более крупных выборках. Это может иметь практическое значение в клинической практике, поскольку повышенная жесткость именно артерий эластического типа связана с высоким риском неблагоприятных сердечно-сосудистых событий, что значительно ухудшает прогноз [17].

Дальнейшее изучение данного вопроса позволит повысить эффективность вторичной профилактики у пациентов с АГ после перенесенного ишемического инфаркта головного мозга.

\section{Bblводы}

1. Полиморфизм генов G894T гена e-NOS, T786C гена e-NOS и G5665T гена EDN-1 не связан с гипотензивным эффектом препаратов.

2. Выявлена взаимосвязь G894T гена e-NOS, T786C гена е-NOS и G5665T гена EDN-1 с эффективностью коррекции дисфункции эндотелия, проявляющейся отсутствием достоверного прироста ЭЗВД у носителей генотипов с рецессивными аллелями.

3. Выявлена взаимосвязь G5665T гена EDN1 с эффективностью коррекции повышенной СРПВ, которая проявляется отсутствием достоверного снижения данного параметра у носителей генотипов с рецессивными аллелями.

\section{Литература}

1. Жесткость сосудистой стенки у пациентов с артериальной гипертензией / О. Д. Остроумова [и др.] // Системные гипертензии. - 2015. - № 2. - С. 43-48.

2. Современные представления о роли артериальной ригидности в патогенезе сердечной недостаточности / И. С. Гончаров [и др.] // Клиническая фармакология и терапия. - 2013. - Т. 22, № 3. - С. 53-60.

3. Состояние параметров жесткости сосудистой стенки у больных артериальной гипертонией на фоне комплексной терапии ци- топротекторами и сартанами / В. П. Михин [и др.] // Архив внутренней медицины. - 2015. - № 5 (25). - C. 40-44.

4. Костюченко, Г. И. Анализ эффективности гипотензивной терапии в группе пациентов молодого возраста в связи с полиморфизмом генов, ассоциированных с артериальной гипертензией / Г. И. Костюченко, О. Г. Вьюн, Л. А. Костюченко // Здоровье и образование в XXI веке. - 2018. - № 2 (20). - С. 46-50.

5. A new equation to estimate glomerular filtration rate / A. Levey [et al.] // Ann. Intern. Med. - 2009. - Vol. 150, № 9. - Р. 604-612.

6. Исследование вазомоторной функции эндотелия плечевой артерии с использованием импедансной технологии у больных атеросклерозом / Л. 3. Полонецкий [и др.] // Медицинская панорама. - 2005. - № 7. - С. 40-43.

7. Петровская, Н. В. Применение антагониста кальция амлодипина для лечения пациентов с артериальной гипертонией / Н. В. Петровская, В. В. Желнов, И. С.

Комарова // Русский медицинский журнал. - 2009. № 18. - С. 1164-1169.

8. $2013 \mathrm{ESH} / \mathrm{ESC}$ Guidelines for the management of arterial hypertension / European Society of Hypertension, European Society of Cardiology ; G. Mancia [et al.] // Journal of Hypertension. - 2013. - Vol. 31, № 7. P. 1281-1357. - doi: 10.1097/01.hjh.0000431740.32696.

9. $2018 \mathrm{ESH} / \mathrm{ESC}$ Guidelines for the management of arterial hypertension / European Society of Hypertension, European Society of Cardiology ; B. Williams [et al.] // Journal of Hypertension. - 2018. - Vol. 36, № 10. P. 1953-2041. - doi: 10.1097/HJH.0000000000001940.

10. Клинико-прогностическое значение полиморфизма гена эндотелиальной NO-синтетазы у больных с острыми коронарными синдромами / А. Н. Пархоменко [и др.] // Медицина неотложных состояний. - 2014. - № 3 (58). - С. 45-53.

11. Бебякова, Н. А. Взаимосвязь периферической вазоконстрикции с полиморфизмом Т-786С гена эндотелиальной синтазы оксида азота / Н. А. Бебякова, А. В. Хромова, О. М. Феликсова // Медицинские науки. - 2013. - № 12. - С. 176-179.

12. Estudio del polimorfismo G198A en el gen EDN1 en pacientes afectados de hypertension arterial pulmonary / G. Pousada [et al.] // Med. Clin. - 2015. - Vol. 144, № 8. P. 348-352.

13. Анализ влияния структурной перестройки промотора гена NOS3 на продукцию вазоактивных эндотелиальных факторов / А. В. Хромова [и др.] // Журнал медико-биологических исследований. - 2015. - № 4. - 
C. 107-115. - doi: 10.17238/issn2308-3174.2015.4.107.

14. Пахомя, Н. С. Роль полиморфизма некоторых генов в реализации артериальной гипертензии / Н. С. Пахомя, О. М. Урясьев, А. В. Шаханов // Земский врач. - 2014. - № 3-4 (24). - C. 21-25.

15. Carotid and brachial intima-media thickness of the allelic variants G894T and T-789C of eNOS in systemic sclerosis patients / A. Martínez-Godínez [et al.] // Rev. Med. Inst. Mex. Seguro Soc. - 2015. - Vol. 53, № 1. - P. 46-52.

16. Полиморфизм гена эндотелиальной NO-синтетазы и структурно-функциональное состояние крупных сосудов у больных гипертонической болезнью с гипертрофией левого желудочка / О. И. Яковлева [и др.] // Артериальная гипертензия. - 2005. - Т. 11, № 3. - С. 195-201.

17. Сергиенко, В. А. Прогностическое значение изменений жесткости сосудистой стенки в развитии сердечно-сосудистых заболеваний при сахарном диабете / В. А. Сергиенко, А. А. Сергиенко // Проблемы эндокринной патологии. - 2017. - № 1. - С. 98-110.

\section{References}

1. Ostroumova OD, Kochetkov AI, Kopchenov II, Guseva TF, Bondarec OV. Zhestkost sosudistoj stenki u pacientov s arterialnoj gipertenziej. Sistemnye gipertenzii. 2015;2: 43-48. (Russian).

2. Goncharov IS, Ahmetov RE, Aleksandrija LG, Villevalde SV, Kotovskaja JuV. Sovremennye predstavlenija o roli arterialnoj rigidnosti $\mathrm{v}$ patogeneze serdechnoj nedostatochnosti. Klinicheskaja farmakologija i terapija. 2013;22(3):53-60. (Russian).

3. Mihin VP, Boldyreva JuA, Chernjatina MA, Gromnackij NI. Sostojanie parametrov zhestkosti sosudistoj stenki u bolnyh arterialnoj gipertoniej na fone kompleksnoj terapii citoprotektorami i sartanami. Arhiv vnutrennej mediciny. 2015;5(25):40-44. (Russian)

4. Kostjuchenko GI, Vjun OG, Kostjuchenko LA. Analiz jeffektivnosti gipotenzivnoj terapii $\mathrm{v}$ gruppe pacientov molodogo vozrasta v svjazi s polimorfizmom genov, associirovannyh s arterialnoj gipertenziej. Zdorove i obrazovanie v XXI veke. 2018;2(20):46-50. (Russian).

5. Levey AS, Stevens LA, Schmid CH, Zhang YL, Castro $\mathrm{AF}$, Feldman HI. A new equation to estimate glomerular filtration rate. Ann. Intern. Med. 2009;150(9):604-612.

6. Poloneckij LZ, Shancilo JeCh, Lahanko LN, Gul LM, Poloneckij OL, Poloneckij IL. Issledovanie vazomotornoj funkcii jendotelija plechevoj arterii $\mathrm{s}$ ispolzovaniem impedansnoj tehnologii u bolnyh aterosklerozom. Medicinskaja panorama. 2005;7:40-43. (Russian).

7. Petrovskaja NV, Zhelnov VV, Komarova IS. Primenenie antagonista kalcija amlodipina dlja lechenija pacientov $\mathrm{s}$ arterialnoj gipertoniej. Russkij medicinskij zhurnal. 2009;18:1164-1169. (Russian).

8. Mancia G, Fagard R, Narkiewicz K, Redón J, Zanchetti A, Böhm M, Christiaens T, Cifkova R, De Backer G, Dominiczak A, Galderisi M, Grobbee DE, Jaarsma T,
Kirchhof P, Kjeldsen SE, Laurent S, Manolis AJ, Nilsson PM, Ruilope LM, Schmieder RE, Sirnes PA, Sleight P, Viigimaa M, Waeber B, Zannad F; European Society of Hypertension; European Society of Cardiology. 2013 ESH/ESC Guidelines for the management of arterial hypertension. Journal of Hypertension. 2013;31(7):12811357. doi: 10.1097/01.hjh.0000431740.32696.

9. Williams B, Mancia G, SpieringW, Rosei EA, Azizi M, Burnier M, Clement DL, Coca A, Simone G, Dominiczak A, Kahan T, Mahfoud F, Redon J, Ruilope L, Zanchetti A, Kerins M, Kjeldsen S, Kreutz R, Laurent S, Lip GYH, McManus R, Narkiewicz K, Ruschitzka F, Schmieder RE, Shlyakhto E, Tsioufis C, Aboyans V, Desormais I; European Society of Hypertension; European Society of Cardiology. 2018 ESH/ESC Guidelines for the management of arterial hypertension. Journal of Hypertension. 2018;36(10):1953-2041. doi: 10.1097/ HJH.0000000000001940.

10. Parhomenko AN, Lutaj JaM, Irkin OI, Kozhuhov SN, Skarzhevskij AA, Dosenko VE, Mojbenko AA. Klinikoprognosticheskoe znachenie polimorfizma gena jendotelialnoj NO-sintetazy u bolnyh s ostrymi koronarnymi sindromami. Medicina neotlozhnyh sostojanij. 2014;3(58):45-53. (Russian).

11. Bebjakova NA, Hromova AV, Feliksova OM. Vzaimosvjaz perifericheskoj vazokonstrikcii s polimorfizmom T-786S gena jendotelialnoj sintazy oksida azota. Medicinskie nauki. 2013;12:176-179. (Russian).

12. Pousada G, Baloira A, Valverde D. Estudio del polimorfismo K198N en el gen EDN1 en pacientes afectados de hypertension arterial pulmonary. Med Clin. 2015;144(8):348-352.

13. Hromova AV, Feliksova OM, Kuba AA, Bebjakova NA. Analiz vlijanija strukturnoj perestrojki promotora gena NOS3 na produkciju vazoaktivnyh jendotelialnyh faktorov. Zhurnal mediko-biologicheskih issledovanij. 2015;4:107115. doi: 10.17238/issn2308-3174.2015.4.107. (Russian).

14. Pahomja NS, Urjasev OM, Shahanov AV. Rol polimorfizma nekotoryh genov v realizacii arterialnoj gipertenzii. Zemskij vrach. 2014;3-4(24):21-25. (Russian).

15. Martínez-Godínez Á, Miliar-García A, Bautista-Jiménez MI, Jandete-Rivera F, Vera-Lastra OL, Jara LJ, BizuetoRosas H, Cruz-Domínguezh MP. Carotid and brachial intima-media thickness of the allelic variants G894T and T-789C of eNOS in systemic sclerosis patients. Rev. Med. Inst. Mex. Seguro Soc. 2015;53(1):46-52.

16. Jakovleva OI, Vahrameeva NV, Larionova VI, Bogdanova MA, Konradi AO. Polimorfizm gena jendotelialnoj NOsintetazy i strukturno-funkcionalnoe sostojanie krupnyh sosudov u bolnyh gipertonicheskoj boleznju s gipertrofiej levogo zheludochka. Arterialnaja gipertenzija. 2005;11(3):195-201. (Russian).

17. Sergienko VA, Sergienko AA. Prognosticheskoe znachenie izmenenij zhestkosti sosudistoj stenki $\mathrm{v}$ razvitii serdechno-sosudistyh zabolevanij pri saharnom diabete. Problemy jendokrinnoj patologii. 2017;1:98-110. (Russian). 


\section{INTERRELATION OF GENES POLYMORPHISM OF THE ENDOTHELIAL NO-SYNTHASE (G894T, T786C) AND THE ENDOTHELIN-1 (G5665T) WITH THE EFFICIENCY OF THERAPY IN PATIENTS WITH ARTERIAL HYPERTENSION AFTER PREVIOUS ISCHEMIC STROKE \\ Kindaliova V. H., Pronko T. P., Stsiapura T. L. \\ Educational Institution "Grodno State Medical University", Grodno, Belarus}

Background. Gene polymorphism of the endothelial NO-synthase (e-NOS) (G894T, T786C) and endothelin-1 (EDN-1) (G5665T) may be associated with a different response of patients with arterial hypertension (AH) to endotheliotropic therapy (ET).

The aim of the study was to investigate the interrelation of the gene polymorphism of the e-NOS (G894T, T786C) and EDN-1 (G5665T) with the efficacy of therapy in patients with arterial hypertension after previous ischemic stroke.

Material and methods: 65 people with arterial hypertension of II degree after previous ischemic stroke were examined. In all the patients, genotypes of e-NOS genes (G894T, T786C) and EDN-1 (G5665T) gene were determined. Endothelial function and vascular wall stiffness parameters were assessed in subgroups of homozygotes for dominant alleles (SGA) and in subgroups containing a recessive allele (SGB) before and after 12 weeks of ET.

Results: Patients of SGB of e-NOS (G894T, T786C) and EDN-1 (G5665T) genes did not show a significant increase in forearm blood flow (FBF) and the percentage of target values of this parameter was lower compared to that in SGA. There was no significant decrease in the pulse wave velocity (PWV) in patients of EDN-1 (G5665T) gene SGB. The percentage of achievement of the target values of $P W V$ in $S G B$ was lower compared to that in SGA.

Conclusions: Gene polymorphism of the e-NOS (G894T, T786C) and EDN-1 (G5665T) is not associated with the hypotensive effect of the drugs. The effect of the G894T e-NOS gene, T786C e-NOS gene and the G5665T EDN-1 gene correlated with the efficacy of endothelial dysfunction correction, which is manifested by the absence of a significant increase in FBF in carriers of genotypes with recessive alleles. The interrelation of the G5665T EDN-1 gene with the efficiency of correction of increased pulse wave velocity has been revealed, which is manifested by the absence of a significant lowering of this parameter in carriers of genotype with recessive alleles.

Keywords: gene polymorphism of endothelial NO-synthase (G894T, T786C) and endothelin-1 (G5665T), vascular wall stiffness, endothelial dysfunction, endotheliotropic therapy, arterial hypertension, ischemic stroke. 